\title{
Genotypic and phenotypic variation of CADASIL among Chinese, Indians and Rungus in Malaysia
}

Tsun-Haw Toh ${ }^{1}$, Kheng-Seang Lim ${ }^{1 *}$, Ching-Ching $\mathrm{Ng}^{2}$, Imran Idris ${ }^{1}$, Sherrini Bazir Ahmad ${ }^{3}$, Thien-Thien Lim ${ }^{4}$, Irene Looi ${ }^{5}$, Ai-Huey Tan ${ }^{1}$, Chung-Kin Chan ${ }^{2}$, Chun-Shen Lim ${ }^{6}$ and Chong-Tin Tan ${ }^{1}$

${ }^{1}$ Division of Neurology, Department of Medicine, University of Malaya, Kuala Lumpur, Malaysia.

${ }^{2}$ Genetics and Molecular Biology, Institute of Biological Sciences, Faculty of Science, University of Malaya, Kuala Lumpur, Malaysia.

${ }^{3}$ Subang Jaya Medical Centre, Kuala Lumpur, Malaysia.

${ }^{4}$ Division of Neurology, Island Hospital, Penang, Malaysia.

${ }^{5}$ Clinical Research Centre, Seberang Jaya Hospital, Penang, Malaysia.

${ }^{6}$ Department of Biochemistry, School of Biomedical Sciences, University of Otago, Dunedin, New Zealand.

* Correspondence: kslimum@gmail.com; Tel.: +603-79494477

Received: 10 June 2019; Accepted: 4 August 2019; Published: 17 August 2019; Corrected: 17 March 2020

Edited by: King-Hwa Ling (Harvard Medical School, Boston, USA)

Reviewed by: Azlina Ahmad Annuar (University of Malaya, Malaysia);

Chumpol Anamnart (Chulalongkorn University, Thailand)

Orignal article: https://doi.org/10.31117/neuroscirn.v2i3.35

Corrigendum: https://doi.org/10.31117/neuroscirn.v3i1.45

\begin{abstract}
Cerebral autosomal dominant arteriopathy with subcortical infarcts and leukoencephalopathy (CADASIL) is a hereditary disease of small cerebral arteries. This case series aims to describe the mutations in NOTCH3 and their phenotypes in Malaysia. We included patients who were genetically confirmed to have CADASIL, diagnosed at the University of Malaya Medical Centre, Malaysia. Family members who fulfilled clinical or imaging criteria, and patients from two previous published Malaysian families were also included. Six families (eleven cases) were included in this series. Genetic testing revealed NOTCH3 mutations in c.328C>T (p.Arg110Cys, R110C), c.553T>G (p.Cys185Gly, C185G), c.1630C >T (p.Arg544Cys, R544C) and c.160C>T (p.Arg54Cys, R54C). Two out of four Chinese families had R544C mutation in exon 11, with a later age of onset, absence of migraine and lack of anterior temporal pole involvement on MRI. One family with mixed Indian and Chinese ancestry had a mutation in exon 3 with R110C and another Indian family exon 4 with C185G mutation. This case series highlights the genotypic and phenotypic variability of CADASIL in a multi-ethnic country. The finding of p.Arg544Cys mutation among the older Chinese families, similar to those reported in Jeju Island and Taiwan, suggest the need to screen the older Chinese stroke patients with typical MRI changes.
\end{abstract}


C2019 by Toh et al. for use and distribution in accord with the Creative Commons Attribution (CC BY-NC 4.0) license (https://creativecommons.org/licenses/by-nc/4.0/), which permits unrestricted non-commercial use, distribution, and reproduction in any medium, provided the original author and source are credited.

\subsection{INTRODUCTION}

Cerebral autosomal dominant arteriopathy with subcortical infarcts and leukoencephalopathy (CADASIL) is a hereditary disease of small cerebral arteries that has been recognised as an important cause of stroke in the younger age group. Clinically, CADASIL is characterised by transient ischaemic attacks (TIA) or ischaemic stroke, migraine with aura, neuropsychiatric symptoms such as depression or bipolar disorder, as well as dementia. Typical neuroimaging features include T2hyperintensities in the periventricular white matter, anterior temporal pole, external capsule, basal ganglia, and brainstem [1]. Mutations in the NOTCH3 (notch receptor 3) gene on chromosome 19p13.2 are responsible for the clinical features in CADASIL, and up to date, more than 270 different NOTCH3 mutations have been identified in CADASIL patients [2] .

The number of CADASIL cases reported in Asia is increasing [2- $\underline{-}]$ with better recognition of the condition and improved access to genetic testing. Few studies have compared the mutation profiles between Asians and Caucasians. Liu et al. [6] found that the mutational spectrum of NOTCH3 in northern China in all confirmed CADASIL patients was mostly in exon 4 and exon 3, similar to Caucasians. However, other studies such as those in eastern and southern China, Taiwan and Korea showed a different result, with the majority being mutations in exon 11 [2-4]. The neuroimaging features in these studies were also different, with a lower percentage (20-45.8\%) of anterior temporal pole involvement and a higher prevalence of intracranial haemorrhage $[\underline{3}, \underline{4}, \underline{7}]$

Previous reported genetically confirmed cases from Malaysia include a Rungus family [ $\underline{8}$ ] and a Chinese Malaysian family who resides in Singapore [ㅁ]. In concordance with the multiethnic diversity of the country, this case series highlights the variations in genotypes and phenotypes among various ethnic groups in Malaysia.

\subsection{METHODS}

Ethics approval was obtained from the ethics committee at the University Malaya Medical Centre (UMMC). All subjects were Malaysian adults who presented to UMMC and fulfilled our screening criteria as shown in Table 1. The subjects must have at least one of the following: 1) stroke-like episodes with permanent neurological signs, 2) migraine, 3) major mood disorder or subcortical dementia. White matter changes in the brain MRI without cortical infarcts is also a requirement, and there should be no vascular risk factors etiologically related to the deficits. We excluded patients who had severe hypertension or complicated heart/ vascular disease, those with severe intracranial stenosis on magnetic resonance angiography (MRA)/ transcranial Doppler (TCD) and those with normal brain magnetic resonance imaging (MRI) at age $>35$ years old. Vascular risk factors included severe hypertension or diabetes mellitus. Severe hypertension is defined as hypertension with target organ damage, including left ventricular hypertrophy, heart failure, coronary artery disease, peripheral vascular disease, proteinuria, glomerular filtration rate $(\mathrm{GFR})<60 \mathrm{ml} / \mathrm{min} / 1.73 \mathrm{~m}^{2}$, papilloedema or haemorrhage and exudates on retinal examination. Complicated heart/vascular disease includes infective endocarditis, congenital heart disease, septal defect, severe heart failure, left ventricular clot, aortic dissection or carotid artery stenosis $>70 \%$.

A total of six patients who fulfilled the criteria above were identified at Neurology Unit, University of Malaya Medical Centre from 2011 until 2017. Out of the six who underwent genetic testing, four were tested positive for CADASIL NOTCH3 mutation. Family members who had features of either a young-onset TIA or ischaemic 
stroke, migraine with aura, neuropsychiatric symptoms such as depression or bipolar disorder, or dementia, were also included.

Table 1. Screening criteria for CADASIL in this study

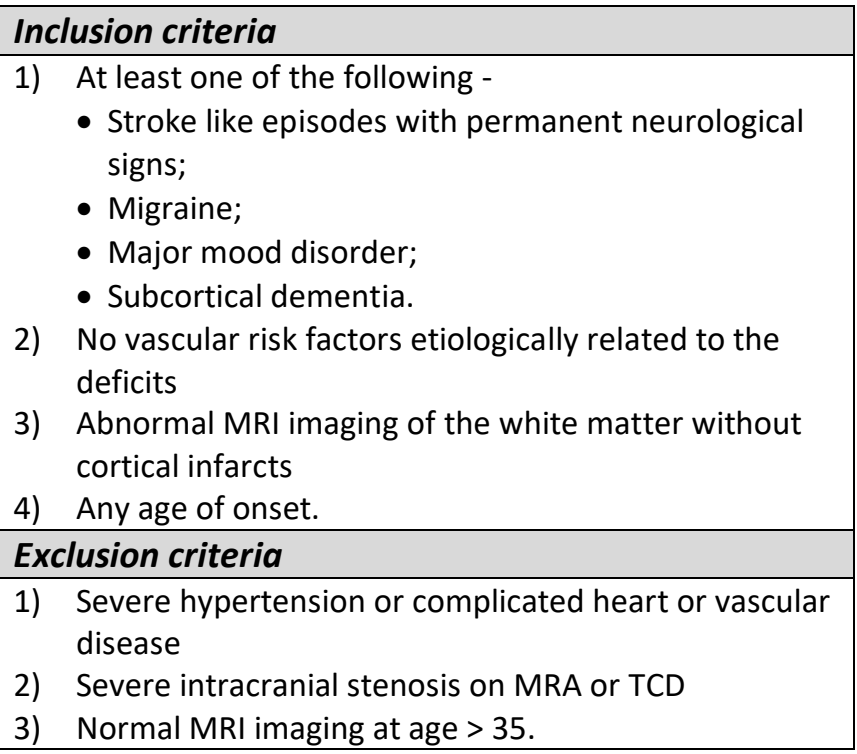

A detailed clinical assessment of the proband and their family members was performed, especially for the presence of stroke, migraine, cognitive dysfunction and psychiatric disorder, using semi-structured interview and structured questionnaires (Supplement Form 1). In addition, new presentations that were not described before were explored. A detailed pedigree was plotted. Cases from the same family were denoted with the same number (such as 3 and 3.1 annotated the proband and her family member respectively). Investigations to exclude other causes of stroke such as electrocardiogram, echocardiography, lipid profile and diabetes screening were also performed.

To have a more complete profile of a Malaysian case series, two previously reported Malaysian families were included in the analysis, consisting of a Rungus family reported by Lim et al. [] and a Malaysian Chinese family by Wilder-Smith et al. []].

\subsection{Neuroimaging study}

The cases underwent MRI of the brain using a 1.5T machine. The MRI sequences utilised were Axial T2W, $T 1 W$, fluid attenuation inversion recovery (FLAIR) and MRA. The lesions seen on MRI were quantified using Scheltens scoring system [ㅇ].

\subsection{Blood samples collection, DNA extraction and mutations screening}

About $3 \mathrm{ml}$ of peripheral blood was collected from each proband. Genomic DNA was extracted using the QIAamp DNA Blood Midi kit (Qiagen, Hilden, Germany) according to the manufacturer's instructions. Twentythree exons of NOTCH3 of the proband were amplified by PCR using Q5 hot start high-fidelity DNA polymerase (NEB, Ipswich, MA, USA) or Phusion Flash high-fidelity PCR master mix (Finnzymes, Thermo Scientific, Lafayette, CA, USA). The PCR products were purified, followed by DNA sequencing. The sequencing results were compared with NOTCH3 RefSeqGene (NM_000435.3). Only those with pathogenic mutations in the coding regions of NOTCH3 were included. Mutations leading to the gain or the loss of a cysteine residue in one of the 34 epidermal growth factor-like repeat (EGFr) domains of the NOTCH3 protein (amino acid residues 40-1373) are likely to be pathogenic [10] .

\subsection{RESULTS}

The demographic and clinical features of the cases are shown in Table 2. Four out of five cases with pure Chinese ethnicity (cases 1, 2, 6, 6.2) were found to have an older age at diagnosis (ranging from 60 to 69 years) and did not have any symptoms of migraine. They were screened for CADASIL due to the presence of stroke and excessive white matter MRI changes without significant vascular risk factors. Two cases had seizures (case 1 and 3), a rare but previously reported symptom in CADASIL. We were also able to uncover some atypical clinical features, including the presence of retinitis pigmentosa in case 3 and a presentation of cerebellar stroke in case 6 . The family pedigrees for cases with a positive family history are shown in Figure 1 . All cases demonstrated the positive family history, except case 2 . 
Table 2. Demographics, clinical features and genotypes of the CADASIL cases

\begin{tabular}{|c|c|c|c|c|c|c|c|c|c|c|c|}
\hline Study & Our study & & & & & Lim et al. (201) & & & Wilder-Smi & th et al. (200 & \\
\hline Case & 1 & 2 & 3 & 3.1 & 4 & 5 & 5.1 & 5.2 & 6 & 6.1 & 6.2 \\
\hline Age (onset) & 68 & 60 & 30 & 20 's & 26 & 42 & 38 & Asymptomatic & 69 & 45 & 60 \\
\hline Gender & Male & Female & Female & Male & Male & Male & Male & Female & Female & Female & Male \\
\hline Ethnicity & Chinese & Chinese & $\begin{array}{l}\text { Mixed Chinese } \\
\text { and Indian }\end{array}$ & $\begin{array}{l}\text { Mixed } \\
\text { Chinese } \\
\text { and Indian } \\
\end{array}$ & Indian & Rungus & Rungus & Rungus & Chinese & Chinese & Chinese \\
\hline $\begin{array}{l}\text { Family } \\
\text { history* }\end{array}$ & $\begin{array}{l}\text { Father and } \\
\text { brother - C }\end{array}$ & $\mathrm{Nil}$ & $\begin{array}{l}\text { Grandmother, } \\
\text { Uncle, Aunty, } \\
\text { Mother, } 2^{\text {nd }} \\
\text { brother - C } \\
\text { Eldest brother - } \\
\text { B }\end{array}$ & & $\begin{array}{l}\text { Grandparents, } \\
\text { Parents, Uncle, } \\
2 \text { cousins - C }\end{array}$ & $\begin{array}{l}\text { Brother - A } \\
\text { Sister - A } \\
\text { (asymptomatic } \\
\text { at 45) } \\
\text { Brother - C } \\
\text { Mother - C } \\
\end{array}$ & & & $\begin{array}{l}\text { Brother - B } \\
\text { Niece - A } \\
\text { Father, } 3 \\
\text { brothers, } \\
2 \text { sisters - C }\end{array}$ & & \\
\hline Hypertension & Yes & No & No & No & No & No & No & No & Yes & No & No \\
\hline Diabetes & No & No & No & No & No & No & No & No & No & No & No \\
\hline Dyslipidaemia & No & No & Yes & No & Yes & Yes & No & No & Yes & No & No \\
\hline Smoking & No & No & No & No & No & No & No & No & No & No & Yes \\
\hline $\begin{array}{l}\text { Initial } \\
\text { symptom }\end{array}$ & $\begin{array}{l}\text { Retrograde } \\
\text { amnesia, } \\
\text { Stroke }\end{array}$ & Stroke & $\begin{array}{l}\text { Migraine with } \\
\text { aura }\end{array}$ & $\begin{array}{l}\text { Migraine } \\
\text { with aura }\end{array}$ & Stroke & $\begin{array}{l}\text { Migraine with } \\
\text { aura }\end{array}$ & Stroke & $\mathrm{Nil}$ & $\begin{array}{l}\text { Stroke } \\
\text { (cerebellar) }\end{array}$ & Stroke & Stroke \\
\hline $\begin{array}{l}\text { Other } \\
\text { manifestations }\end{array}$ & Seizure & $\mathrm{Nil}$ & $\begin{array}{l}\text { Encephalopathy, } \\
\text { Retinitis } \\
\text { pigmentosa, } \\
\text { Stroke, Seizures }\end{array}$ & $\begin{array}{l}\text { Stroke, } \\
\text { Cognitive } \\
\text { impairment }\end{array}$ & $\begin{array}{l}\text { Migraine, } \\
\text { Encephalopathy }\end{array}$ & $\mathrm{Nil}$ & $\begin{array}{l}\text { Gelastic } \\
\text { dementia }\end{array}$ & $\mathrm{Nil}$ & $\mathrm{Nil}$ & $\begin{array}{l}\text { Cognitive } \\
\text { impairment }\end{array}$ & Dementia \\
\hline $\begin{array}{l}\text { Coding } \\
\text { sequence } \\
\text { change }\end{array}$ & c. $1630 \mathrm{C}>\mathrm{T}$ & c. $1630 \mathrm{C}>\mathrm{T}$ & $\mathrm{c} .328 \mathrm{C}>\mathrm{T}$ & NA & c. $553 \mathrm{~T}>\mathrm{G}$ & c. $160 C>T$ & c. $160 C>T$ & c. $160 C>T$ & c. $328 C>T$ & c. $328 C>T$ & c. $328 \mathrm{C}>\mathrm{T}$ \\
\hline $\begin{array}{l}\text { Amino acid } \\
\text { change }\end{array}$ & R544C & R544C & R110C & NA & C185G & R54C & R54C & R54C & R110C & R110C & R110C \\
\hline Exon & 11 & 11 & 3 & NA & 4 & 2 & 2 & 2 & 3 & 3 & 3 \\
\hline Skin biopsy" & NA & NA & NA & NA & NA & GOM+ & NA & NA & GOM+ & GOM+ & NA \\
\hline
\end{tabular}

* A - Genetic/ biopsy; B - Clinical + MRI changes; C - Clinical (stroke/ TIA/ dementia/ psychiatric features); \# GOM - granular osmophilic material; NA - Not available 
Table 3. Scheltens scores of the CADASIL cases

\begin{tabular}{|c|c|c|c|c|c|c|c|c|}
\hline Case & 1 & 2 & 3 & 3.1 & 4 & 5 & 5.1 & 5.2 \\
\hline \multicolumn{9}{|l|}{ Periventricular hyperintensities ${ }^{1}$ (PVH 0-6) } \\
\hline Capsular occipital & 2 & 1 & 2 & 2 & 2 & 2 & 2 & 1 \\
\hline Capsular frontal & 2 & 2 & 1 & 2 & 1 & 2 & 2 & 1 \\
\hline Bands lateral ventricle & 2 & 1 & 1 & 1 & 2 & 2 & 2 & 1 \\
\hline \multicolumn{9}{|l|}{ White matter hyperintensities ${ }^{2}$ (WMH 0-24) } \\
\hline Frontal & 6 & 6 & 6 & 6 & 6 & 6 & 6 & 4 \\
\hline Parietal & 6 & 6 & 1 & 6 & 6 & 6 & 6 & 4 \\
\hline Temporal & 0 & 0 & 3 & 3 & 3 & 6 & 6 & 0 \\
\hline Occipital & 6 & 0 & 1 & 5 & 6 & 0 & 6 & 0 \\
\hline \multicolumn{9}{|l|}{ Basal ganglia hyperintensities ${ }^{2}$ (BG 0-30) } \\
\hline Caudate & 3 & 1 & 0 & 0 & 1 & 3 & 0 & 0 \\
\hline Putamen & 1 & 2 & 3 & 0 & 1 & 3 & 0 & 0 \\
\hline Globus pallidus (GP) & 0 & 1 & 0 & 3 & 2 & 0 & 0 & 0 \\
\hline Thalamus & 0 & 2 & 0 & 1 & 1 & 0 & 4 & 0 \\
\hline Internal capsule & 1 & 1 & 3 & 2 & 3 & 3 & 3 & 3 \\
\hline \multicolumn{9}{|l|}{ Infratentorial foci of hyperintensity ${ }^{2}$ (ITF 0-24) } \\
\hline Cerebellum & 0 & 0 & 0 & 0 & 0 & 0 & 3 & 0 \\
\hline Midbrain & 0 & 0 & 0 & 0 & 0 & 0 & 3 & 0 \\
\hline Pons & 1 & 1 & 0 & 0 & 0 & 0 & 3 & 4 \\
\hline Medulla & 0 & 1 & 0 & 0 & 0 & 0 & 3 & 0 \\
\hline Total & 30 & 25 & 21 & 31 & 34 & 33 & 50 & 17 \\
\hline \multicolumn{9}{|l|}{ Other findings ${ }^{3}$} \\
\hline Projection fibers (Internal capsule posterior limb) & 0 & 1 & 1 & 1 & 2 & 1 & 2 & 0 \\
\hline \multicolumn{9}{|l|}{ Temporal white matter } \\
\hline Anterior to posterior margin of amygdala & 1 & 0 & 2 & 1 & 1 & 3 & 3 & 0 \\
\hline Posterior to posterior margin of amygdala & 0 & 1 & 0 & 1 & 0 & 1 & 1 & 0 \\
\hline External capsule & 1 & 2 & 1 & 2 & 3 & 3 & 3 & 0 \\
\hline Atrophy ${ }^{4}$ & 1 & 1 & 0 & 0 & 1 & 1 & 2 & 0 \\
\hline
\end{tabular}

${ }^{1} 0=$ absent; $1=0$ to $5 \mathrm{~mm} ; 2=>5 \mathrm{~mm}$

${ }^{2} 0=$ absent; $1=$ up to five lesions of $<3 \mathrm{~mm}$ diameter; $2=$ six or more lesions of $<3 \mathrm{~mm} ; 3=$ up to five lesions 4 to $10 \mathrm{~mm}$ in diameter; $4=$ six or more lesions of 4 to $10 \mathrm{~mm} ; 5=$ one or more lesions $10 \mathrm{~mm}$ in size; and $6=$ confluent hyperintensity

${ }^{3} 0=$ absent, $1=<5$ lesions, $2=5-10$ lesions, $3=>10$ lesions

${ }^{4} 0=$ absent, 1 = mild, 2 = moderate, $3=$ severe (sulcal, cerebellar folia prominence, enlargement of ventricles, brainstem size)

\subsection{Neuroimaging findings}

Figure 2 shows the axial MRI features for cases 1, 3 and 4 with the involvement of basal ganglia, anterior temporal pole and periventricular regions, respectively. Scheltens scoring of the MRI brain for all cases are shown in Table 3. The scoring for some family members and the cases reported by Wilder-Smith et al. []] were not included as there were either no MRI brain or no access to the MRI images. All the available cases demonstrated T2-lesions in the periventricular and white matter regions of the frontal and parietal lobes, with the involvement of the internal capsule. All cases showed external capsule involvement except an asymptomatic case (5.2). Cases 1, 2, 5.1 and 5.2 showed white matter changes of the infratentorial structures, namely brainstem and cerebellum. Cases 1, 2 and 5.2 showed no involvement of the temporal pole. All the subjects demonstrated normal MR angiographic findings with no evidence of intracranial vascular stenosis seen. Cerebral atrophy was more prominent in the subjects with the higher Scheltens score. Case 1, 3 and 4 showed no blooming artefacts on gradient echo (GRE) or susceptibility weighted imaging (SWI) sequences. These sequences were not available in other cases. 




Case 3
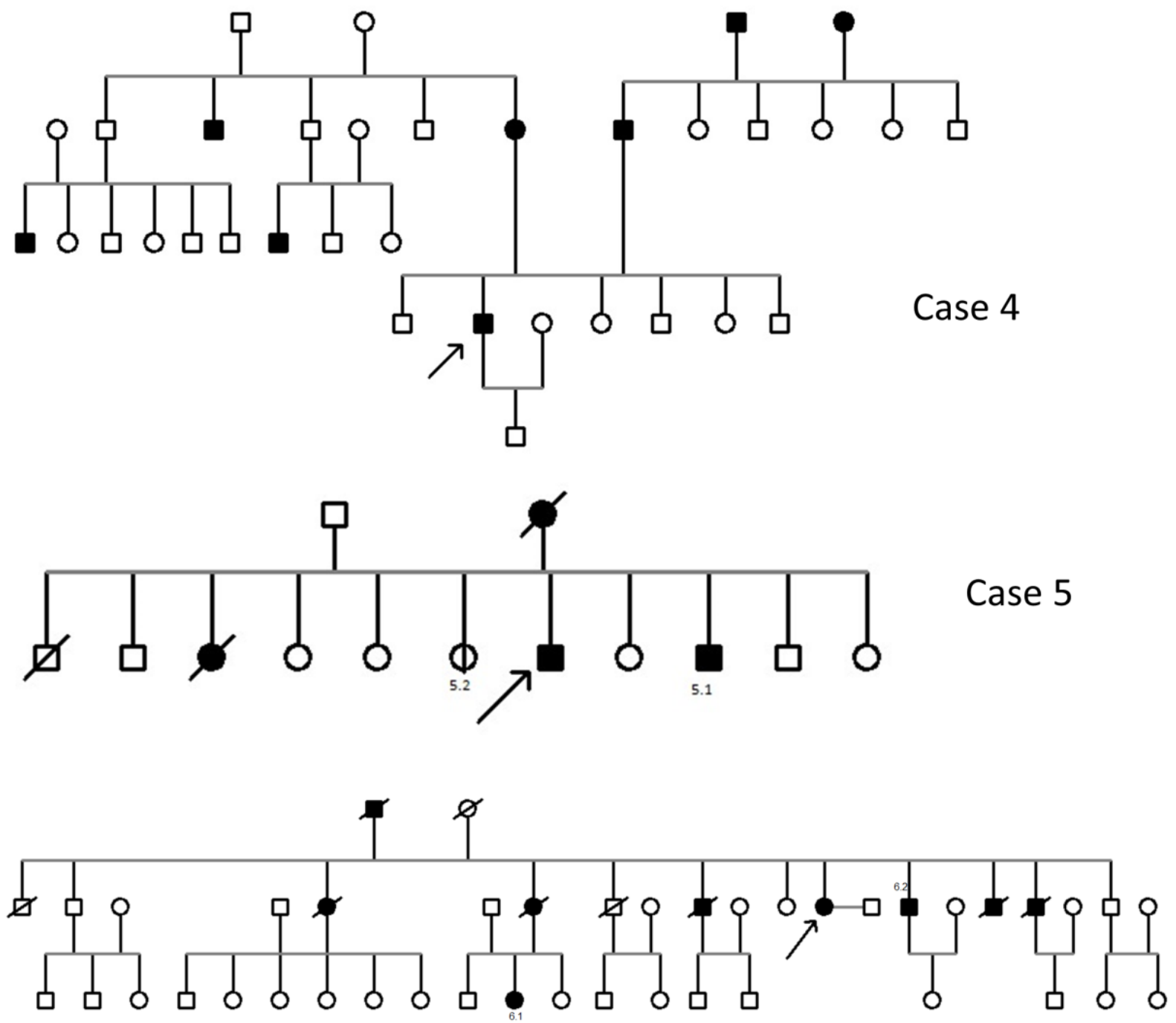

Case 6

Figure 1. Pedigrees for the families affected by CADASIL (cases 3-6). Square and circle denote male and female, respectively. Solid square and circle denote affected male and female, respectively. Vertical band denotes asymptomatic mutation carrier. The proband for each family is denoted with an arrow. A strikethrough denotes a deceased member. 


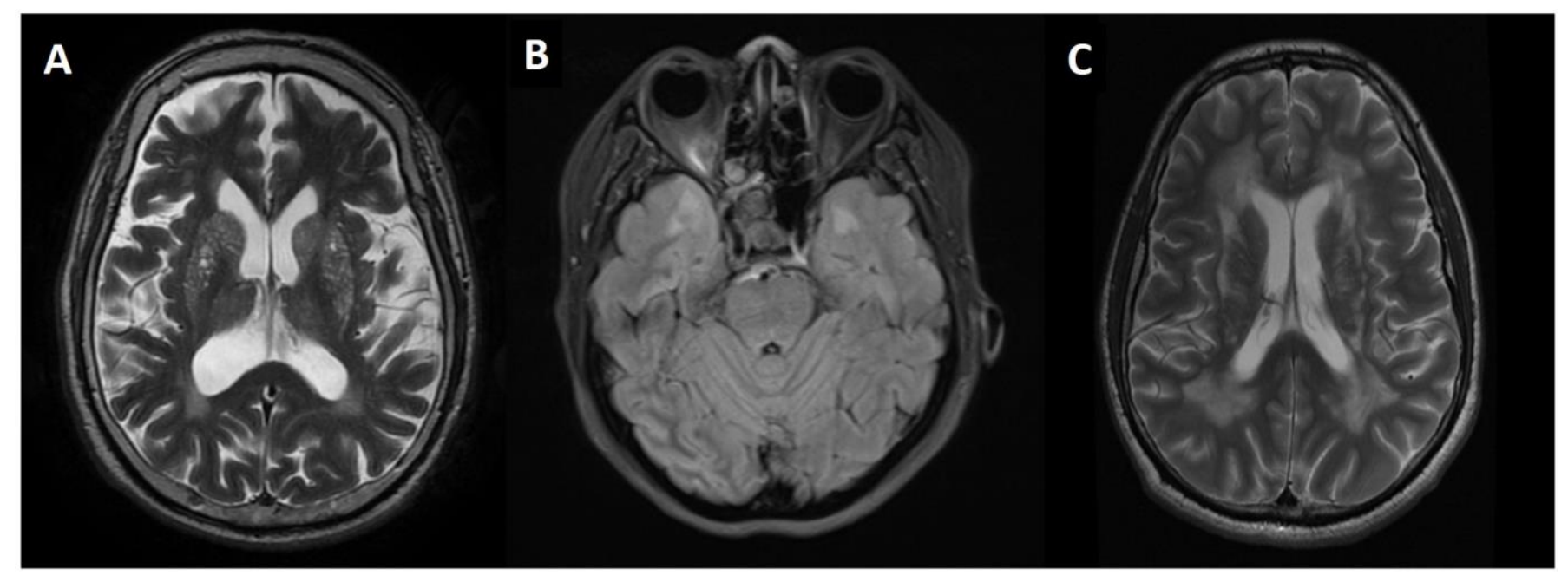

Figure 2. (A) Axial T2W MRI brain of case 1 demonstrates hyperintensities in caudate nucleus, lentiform nucleus. (B) Axial FLAIR sequence of case 3 demonstrates anterior temporal pole involvement. (C) Axial T2W MRI brain of case 4 demonstrates confluent deep white matter and periventricular lesions.

\subsection{NOTCH3 mutations}

We sequenced exons 2 to 24 of NOTCH3 of the proband. Exons 2-24 encode 34 EGFr domains of NOTCH3 [11]. Three different cysteine-altering missense mutations were identified from Case 1 - 4 (Figure 3). In our series, two Chinese patients had a heterozygous mutation in exon 11 with c.1630C >T (p.Arg544Cys, R544C). One family with mixed Indian and Chinese ancestry had a heterozygous mutation in exon 3 with c.328C $>\mathrm{T}$ (p.Arg110Cys, R110C). Another Indian family was detected to have a heterozygous mutation in exon 4 with c.553T>G (p.Cys185Gly, C185G).

\subsection{DISCUSSION}

This series included four different mutations in exon 2, 3, 4 and 11 of the NOTCH3 gene from 3 different ethnic groups with diverse phenotypic variations including the age of onset and presenting symptoms. Some studies reported a weak genotype-phenotype correlation for CADASIL, even within the same pedigree $[\underline{12}, \underline{13}]$. Other modulating factors, such as hypertension and smoking have been shown to influence disease severity [12]. Despite the diverse phenotypic variations, a few mutations have been associated with certain unique phenotypes. Opherk et al. [14] demonstrated that the C117F mutation was associated with earlier mortality and $\mathrm{C} 174 \mathrm{Y}$ mutation with a lower age of stroke onset.
The R153C mutation was significantly associated with the presence of microbleeds [15]. A worse profile of white matter lesions has been noted in the C440G mutation [16]. Another mutation that has been associated with its own unique phenotype is R544C. Other than the older age of onset, R544C mutation is associated with a higher incidence of intracranial haemorrhage, rarer occurrence of migraine, a higher percentage of cognitive dysfunction and lower frequency of anterior temporal pole involvement $[\underline{3}, \underline{4}, \underline{7}]$. These features can also be seen in our cases with R544C mutation where both cases showed later age of onset and no migraine. The MRI for these two patients also showed a lack of anterior temporal pole involvement.

The R544C mutation is highly prevalent in the CADASIL cohorts reported in Taiwan (70.5\%) [4] and Jeju Island of Korea (75-90.3\%) [ $\underline{3}, \underline{17}]$. It also accounts for a small proportion of CADASIL patients in mainland Korea (27.6\%) [18] and China (2.3-15.5\%) [2, $\underline{6}, \underline{19}]$. Chen et al. [2] reported that the patients carrying R544C mutation in Taiwan and Fujian (China) might be descendants from a common ancestor. The high incidence of R544C in the island of Jeju is also postulated to be due to the founder effect. 


\section{Case 1 c.1630C>T}

足 $\quad \bar{G}$ A Forward

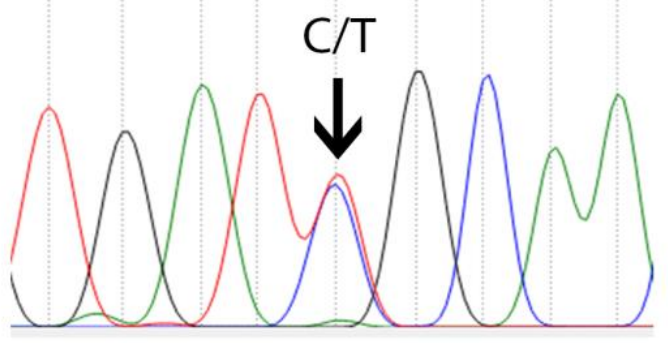

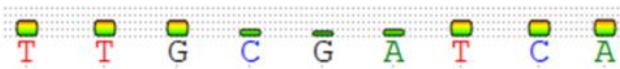
Reverse

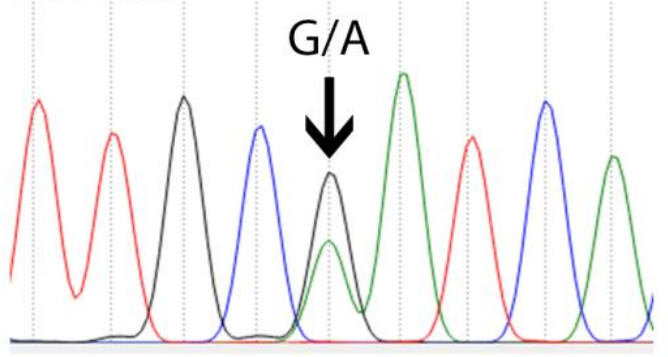

\section{Case 3}

c. $328 C>T$

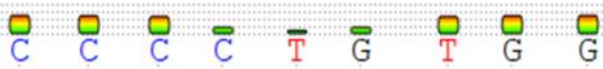
Forward

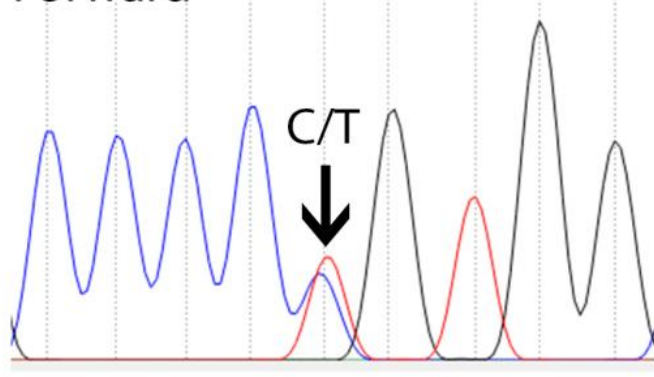

$$
\begin{array}{lllllllll}
\stackrel{C}{C} & \bar{C} & \bar{A} & \bar{C} & \bar{G} & \bar{G} & \vec{G} & \vec{G}
\end{array}
$$

Reverse

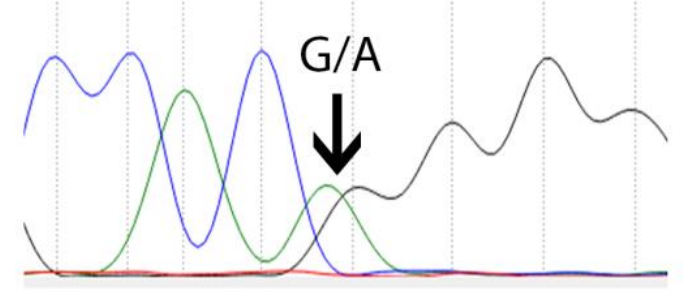

\section{Case 2 c.1630C>T}

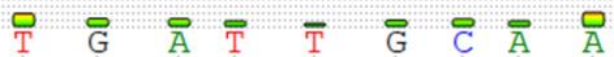

Forward

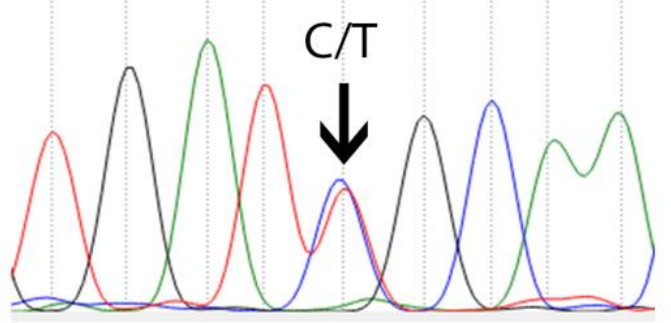

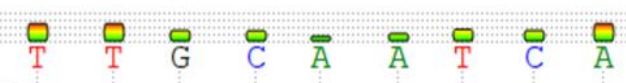

Reverse

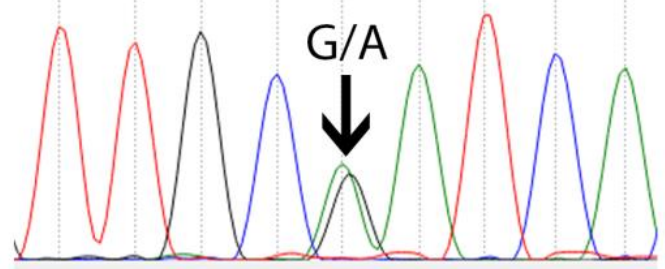

Case 4 c.553T $>\mathrm{G}$

$\begin{array}{lllllllll}\stackrel{C}{C} & \stackrel{C}{C} & \stackrel{A}{A} & \bar{G} & \bar{G} & \bar{G} & \stackrel{0}{T} & \stackrel{Q}{C} & \stackrel{Q}{C}\end{array}$

Forward

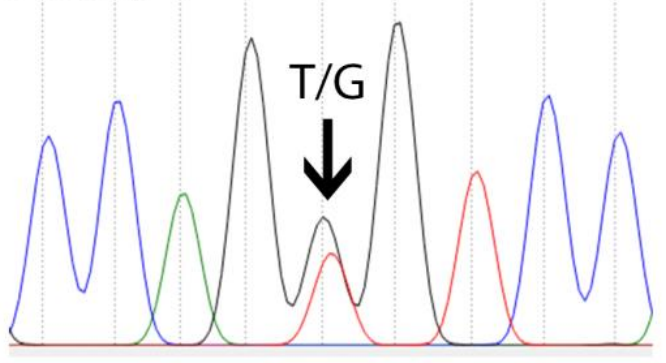

$\begin{array}{lllllllll}G & G & O & \bar{C} & \bar{A} & \bar{C} & \stackrel{O}{T} & G & G \\ G & G & G\end{array}$

Reverse

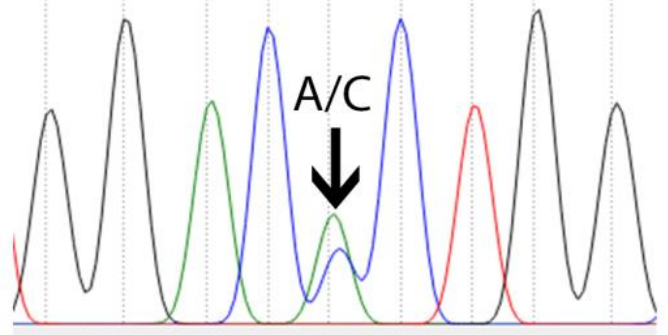

Figure 3. Mutation analysis of the NOTCH3 gene by direct DNA sequencing. Partial sequencing chromatograms (forward and reverse strand) revealed the heterozygous missense mutation in Case 1-4. 
The family tree for Case 3, who is of mixed Chinese and Indian ancestry shows that the origin of the mutation is likely from the maternal Chinese side of the family. Out of the four Chinese families in this series, a high proportion (50\%) of them had R544C mutation. There seemed to be a suggestion of a link between the Malaysian Chinese and the population of Han Chinese in Taiwan, Fujian and the Koreans in Jeju Island, though this remains a postulate as the number of patients in this series is low. Interestingly, both our R544C patients are of Hakka dialect while the majority of Han Chinese in Taiwan/ Fujian are of Hokkien dialect. Cross marriage between various Chinese dialect groups is common in Southeast Asian countries, including Malaysia, which may explain the finding.

There are also two families with South Asian ancestry included in our series, with mutations in R110C (exon 3, case 3) and C185G (exon 4, case 4), of which both mutations had been previously reported in European populations $[\underline{14}, \underline{20}]$. To the best of our knowledge, 22 cases (a family of 17 members and five other individual cases) of CADASIL have been reported in individuals with South Asian ancestry (Indian and Sri Lankan) so far. Out of those, only eight were genetically confirmed. The mutations found included R141C mutation (exon 4) in six cases from two families, C260G (exon 5) and C144S (exon 4) in one case each [21-26]. The relatively lower number of genetically confirmed cases reported from the South Asian region could be due to underrecognition of the condition and the difficulty in access to genetic screening.

This case series has several limitations. The number of cases is small due to single centre recruitment and the lack of prospective screening protocol, thus limiting a broader application of the results from this study. The family pedigree is incomplete for case 1 and 3 , due to patients' difficulties in providing detailed information on their family history. Due to the retrospective nature of the study, specific MRI sequences were not obtained and resulted in an incomplete analysis.

\subsection{CONCLUSION}

This case series highlights the various genotype and phenotype spectrum in our multiethnic country. A more extensive study, including more positive cases, is needed to further map out the different CADASIL genotypes in Malaysia.

Supplementary Materials: The questionnaire used for obtaining clinical data from the proband and family members available online at

https://doi.org/10.31117/neuroscirn.v2i3.35.

Acknowledgements: This work was supported by University of Malaya Research Grant (RG517-13HTM), University of Malaya, to K.-S.L. and High Impact Research Grant (UMMOHE UM.C/625/1/HIR/MOHE/ CHAN-02 H-50001A000023), University of Malaya, to C.-C.N. We thank the affected individuals and their families for participating in this study.

Author Contributions: T.-H.T., K.-S.L. and C.-C.N. contributed in the acquisition, interpretation of data for the work, drafting, critical revision and final approval. I.I., S.B.A., T.-T.L., I.L., A.-H.T., C.-K.C., C.-S.L. had substantial contributions to the acquisition, interpretation of data for the work and critical revision. C.-T.T. had substantial contributions to the conception or design of the work, analysis, or interpretation of data for the work, critical revision, and final approval.

Conflicts of Interest: Funding sponsors had no role in the study design, collection, analysis and interpretation of data, writing of the report and in the decision to submit the article for publication.

\section{References}

1. Stojanov D, Vojinovic S, Aracki-Trenkic A, Tasic A, Benedeto-Stojanov D, Ljubisavljevic S, et al. Imaging characteristics of cerebral autosomal dominant arteriopathy with subcortical infarcts and leucoencephalopathy (CADASIL). Bosn J Basic Med Sci. 2015;15(1):1-8. https://doi.org/10.17305/bjbms.2015.247 
2. Chen S, Ni W, Yin X-Z, Liu H-Q, Lu C, Zheng Q-J, et al. Clinical features and mutation spectrum in Chinese patients with CADASIL: A multicenter retrospective study. CNS Neurosci Ther. 2017;23(9):707-716. https://doi.org/10.1111/cns.12719

3. Choi JC, Kang S-Y, Kang J-H, Park J-K. Intracerebral hemorrhages in CADASIL. Neurology. 2006;67(11):2042-2044. https://doi.org/10.1212/01.wnl.0000246601.70918.06

4. Liao Y-C, Hsiao C-T, Fuh J-L, Chern C-M, Lee W-J, Guo Y-C, et al. Characterization of CADASIL among the Han Chinese in Taiwan: Distinct Genotypic and Phenotypic Profiles. PLoS ONE. 2015;10(8):e0136501. https://doi.org/10.1371/journal.pone.0136501

5. Wilder-Smith E, Shen Y, Ng YK, Yu GX, Chew NK, Tan CT, et al. Cerebral autosomal dominant arteriopathy with subcortical infarcts and leukoencephalopathy (CADASIL) in a Chinese family: clinical, radiological and skin biopsy features. J Clin Neurosci. 2004;11(3):304-307. https://doi.org/10.1016/j.jocn.2003.05.007

6. Liu X, Zuo Y, Sun W, Zhang W, Lv H, Huang Y, et al. The genetic spectrum and the evaluation of CADASIL screening scale in Chinese patients with NOTCH3 mutations. J Neurol Sci. 2015;354(1-2):63-69.

https://doi.org/10.1016/i.jns.2015.04.047

7. Lee Y-C, Liu C-S, Chang M-H, Lin K-P, Fuh J-L, Lu Y-C, et al. Population-specific spectrum of NOTCH3 mutations, MRI features and founder effect of CADASIL in Chinese. J Neurol. 2009;256(2):249-255. https://doi.org/10.1007/s00415-009$\underline{0091-3}$

8. Lim K-S, Tan A-H, Lim C-S, Chua K-H, Lee P-C, Ramli N, et al. R54C Mutation of NOTCH3 Gene in the First Rungus Family with CADASIL. PLOS ONE. 2015;10(8):e0135470. https://doi.org/10.1371/journal.pone.0135470

9. Scheltens P, Barkhof F, Leys D, Pruvo JP, Nauta JJ, Vermersch P, et al. A semiquantative rating scale for the assessment of signal hyperintensities on magnetic resonance imaging. J Neurol Sci. 1993;114(1):7-12. https://doi.org/10.1016/0022510x(93)90041-v

10. Rutten JW, Haan J, Terwindt GM, van Duinen SG, Boon EMJ, Oberstein SAJL. Interpretation of NOTCH3 mutations in the diagnosis of CADASIL. Expert Rev Mol Diagn. 2014;14(5):593-603. https://doi.org/10.1586/14737159.2014.922880

11. Rutten JW, Dauwerse HG, Gravesteijn G, van Belzen MJ, van der Grond J, Polke JM, et al. Archetypal NOTCH3 mutations frequent in public exome: implications for CADASIL. Ann Clin Transl Neurol. 2016;3(11):844-853. https://doi.org/10.1002/acn3.344

12. Adib-Samii P, Brice G, Martin RJ, Markus HS. Clinical spectrum of CADASIL and the effect of cardiovascular risk factors on phenotype: study in 200 consecutively recruited individuals. Stroke. 2010;41(4):630-634. https://doi.org/10.1161/STROKEAHA.109.568402

13. Dichgans M. Cerebral autosomal dominant arteriopathy with subcortical infarcts and leukoencephalopathy: phenotypic and mutational spectrum. J Neurol Sci. 2002;203-204(Special_Issue):77-80. https://doi.org/10.1016/s0022$\underline{510 \times(02) 00270-8}$

14. Opherk C, Peters N, Herzog J, Luedtke R, Dichgans M. Long-term prognosis and causes of death in CADASIL: a retrospective study in 411 patients. Brain. 2004;127(Pt 11):2533-2539. https://doi.org/10.1093/brain/awh282

15. Oberstein SAL, van den Boom R, van Buchem MA, van Houwelingen HC, Bakker E, Vollebregt E, et al. Cerebral microbleeds in CADASIL. Phys Ther. 2001;57(6):1066-1070. https://doi.org/10.1212/wnl.57.6.1066

16. Singhal S, Bevan S, Barrick T, Rich P, Markus HS. The influence of genetic and cardiovascular risk factors on the CADASIL phenotype. Brain. 2004;127(Pt 9):2031-2038. https://doi.org/10.1093/brain/awh223

17. Choi JC, Song S-K, Lee JS, Kang S-Y, Kang J-H. Diversity of stroke presentation in CADASIL: study from patients harboring the predominant NOTCH3 mutation R544C. J Stroke Cerebrovasc Dis. 2011;22(2):126-131. https://doi.org/10.1016/j.jstrokecerebrovasdis.2011.07.002

18. Kim Y-E, Yoon CW, Seo SW, Ki C-S, Kim YB, Kim J-W, et al. Spectrum of NOTCH3 mutations in Korean patients with clinically suspicious cerebral autosomal dominant arteriopathy with subcortical infarcts and leukoencephalopathy. $J$ Neurol Sci. 2013;35(3):726.e1-6. https://doi.org/10.1016/j.neurobiolaging.2013.09.004 
19. Tan Q-C, Zhang J-T, Cui R-T, Xu Q-G, Huang X-S, Yu S-Y. Characteristics of CADASIL in Chinese mainland patients. Neurol India. 2014;62(3):257-261. https://doi.org/10.4103/0028-3886.136900

20. Joutel A, Favrole $P$, Labauge $P$, Chabriat $H$, Lescoat $C$, Andreux F, et al. Skin biopsy immunostaining with a Notch3 monoclonal antibody for CADASIL diagnosis. Lancet. 2002;358(9298):2049-2051. https://doi.org/10.1016/S0140$6736(01) 07142-2$

21. Panagariya A, Sharma B, Shubhakaran. CADASIL in a family from north-west India. J Assoc Physicians India. 2004;52:580581. https://www.ncbi.nlm.nih.gov/pubmed/15645988

22. Gurumukhani JK, Ursekar M, Singhal BS. Cerebral autosomal dominant arteriopathy with subcortical infarcts and leucoencephalopathy (CADASIL): a case report with review of literature. Neurol India. 2004;52(1):99-101. https://www.ncbi.nlm.nih.gov/pubmed/15069251

23. Yadav S, Bentley P, Srivastava P, Prasad K, Sharma P. The first Indian-origin family with genetically proven cerebral autosomal dominant arteriopathy with subcortical infarcts and leukoencephalopathy (CADASIL). J Neurol Sci.

2011;22(1):28-31. https://doi.org/10.1016/i.jstrokecerebrovasdis.2011.05.023

24. Nandhagopal R. CADASIL - Cerebral Autosomal Dominant Arteriopathy with Subcortical Infarcts and Leukoencephalopathy. Sultan Qaboos Univ Med J. 2011;11(2):284-285.

25. De Silva KRD, Gamage R, Dunuwille J, Gunarathna D, Sirisena D, Weerasinghe A, et al. Cerebral autosomal dominant arteriopathy with subcortical infarcts and leukoencephalopathy (CADASIL): a patient from Sri Lanka. J Neurol Sci. 2009;16(11):1492-1493. https://doi.org/10.1016/i.jocn.2009.01.019

26. Eswaradass VP, Ramasamy B, Kalidoss R, Gnanagurusamy G. Cadasil coma: Unusual cause for acute encephalopathy. Ann Indian Acad Neurol. 2015;18(4):483-484. https://doi.org/10.4103/0972-2327.160072 